\title{
Radiation Therapy for Anal Squamous Cell Carcinoma: A Retrospective Multicenter Study
}

\author{
HYEON KANG KOH ${ }^{1}$, KYUBO KIM ${ }^{2}$, WON IL JANG ${ }^{3}$, CHANG HOON SONG ${ }^{4}$, AH RAM CHANG ${ }^{5}$, \\ HAE JIN PARK ${ }^{6}$, KYUNG SU KIM ${ }^{7}$, JI HYUN CHANG ${ }^{8}$ and MI-SOOK KIM ${ }^{3}$ \\ ${ }^{1}$ Department of Radiation Oncology, Konkuk University Medical Center, Seoul, Republic of Korea; \\ ${ }^{2}$ Department of Radiation Oncology, Ewha Womans University College of Medicine, Seoul, Republic of Korea; \\ ${ }^{3}$ Department of Radiation Oncology, Korea Institute of Radiological and Medical Sciences, Seoul, Republic of Korea; \\ ${ }^{4}$ Department of Radiation Oncology, Seoul National University Bundang Hospital, Seongnam-si, Republic of Korea; \\ ${ }^{5}$ Department of Radiation Oncology, Soonchunhyang University Seoul Hospital, \\ Soonchunhyang University College of Medicine, Seoul, Republic of Korea; \\ ${ }^{6}$ Department of Radiation Oncology, Hanyang University College of Medicine, Seoul, Republic of Korea; \\ ${ }^{7}$ Department of Radiation Oncology, Dongnam Institute of Radiological \\ and Medical Sciences, Busan, Republic of Korea \\ ${ }^{8}$ Department of Radiation Oncology, Seoul Metropolitan Government Seoul National \\ University Boramae Medical Center, Seoul, Republic of Korea
}

\begin{abstract}
Aim: To analyze the treatment outcomes, patterns of failures and prognostic factors for patients with anal cancer treated with radiotherapy (RT). Materials and Methods: Between January 2000 and December 2015, 83 patients with anal squamous cell carcinoma were treated with definitive RT. The median $R T$ dose applied to the primary carcinoma site was 55 (range=45-64) Gy. Seventy-six patients (91.6\%) received concurrent chemotherapy, and the most common regimen was 5-fluorouracil plus mitomycin C. Results: The median age of patients was 64 (range=36-86) years, and there were 21 males and 62 females. The overall complete remission rate was $89.2 \%$. The median duration of follow-up was 51 (range=3173) months. The actuarial 5-year overall, progression-free survival (PFS), locoregional progression-free, and distant metastasis-free survival rates were $85.0 \%, 70.4 \%, 78.2 \%$, and $82.6 \%$, respectively. On multivariate analysis, eventual treatment response was the only prognostic factor for overall $(p=0.023)$ and progression-free $(p<0.001)$ survival. Age
\end{abstract}

Correspondence to: Kyubo Kim, MD, Department of Radiation Oncology, Ewha Womans University College of Medicine, 1071 Anyangcheon-ro Yangcheon-gu, Seoul, 07985, Republic of Korea. E-mail: kyubokim.ro@gmail.com and Mi-Sook Kim, MD Department of Radiation Oncology, Korea Institute of Radiological and Medical Sciences, 75 Nowon-ro, Nowon-gu, Seoul, 01812, Republic of Korea. E-mail: mskim@kirams.re.kr

Key Words: Anal cancer, radiotherapy, treatment outcome, pattern of failure, prognostic factor. $(p=0.013)$ and eventual treatment response $(p<0.001)$ were significantly associated with locoregional progression-free survival. Initial treatment response, lymph node involvement and RT technique significantly affected distant metastasis-free survival ( $p=0.016,0.048$ and 0.002 , respectively). Conclusion: $R T$, mainly with concurrent chemotherapy, showed acceptable treatment outcomes and safe toxicity profiles.

Anal cancer is a rare malignancy that comprises only $2.7 \%$ of all digestive system malignancies, with about 8,600 cases newly diagnosed in the United States annually (1). In Korea, anal cancer comprises only $0.1 \%$ of all malignancies (2).

Historically, the treatment of choice for anal cancer has been abdominoperineal resection. However, since its introduction by Nigro et al. (3), concurrent chemoradiotherapy (CCRT) has been a standard therapy for anal squamous cell carcinoma, with radical surgery reserved for salvage treatment in the event of recurrence (4). Despite the low incidence of anal cancer, six randomized phase III trials have successfully established a key treatment for anal cancer. Firstly, CCRT versus radiotherapy (RT) alone was examined, with CCRT proving to be superior to RT alone regarding local or locoregional control and anal cancer-specific survival $(5,6)$. As a chemotherapy regimen for CCRT, a 5-fluorouracil (5-FU) plus mitomycin $\mathrm{C}$ (FM) regimen proved to be more beneficial for local control, colostomy-free survival and disease-free survival than 5-FU alone (7). Moreover, an FM regimen achieved better progression-free survival (PFS) and overall survival (OS) than induction chemotherapy consisting of 5-FU and cisplatin followed by CCRT with the same chemotherapy 
regimen (8). Lastly, the addition of induction or maintenance chemotherapy to CCRT failed to show any benefit $(9,10)$. Therefore, the current treatment of choice for anal cancer is CCRT with an FM regimen. However, many questions remain concerning the best RT protocol, especially concerning optimal dose and field (4).

In this study, we aimed to evaluate the treatment outcomes, patterns of failures, and prognostic factors for patients with anal cancer treated with RT at eight Institutions in Korea. The impact of RT dose and field were also analyzed.

\section{Patients and Methods}

Patient population. The medical records of 86 patients who underwent definitive RT for anal cancer between January 2000 and December 2015 at eight institutions in Korea were retrospectively reviewed. Three patients that had received neoadjuvant chemotherapy before RT were excluded, leaving 83 patients in the final analysis. The Institutional Review Boards of each participating institution approved the study.

All patients had the diagnosis of anal squamous cell carcinoma confirmed by endoscopic biopsy. For the staging workup, abdominopelvic computed tomography (CT) was performed in 81 patients $(97.6 \%)$, pelvic magnetic resonance imaging in $38(45.9 \%)$ and positron emission tomography-CT in 42 (50.6\%).

Treatment. All patients underwent RT with curative intent. The RT target volume encompassed the primary site, pelvic lymph node (LN) area and inguinal $\mathrm{LN}$ area. All patients received RT to the primary site, with a median RT dose of 55 (range=45-64) Gy. Every patient except one received elective RT to the uninvolved pelvic LN area, with a median RT dose of 45 (range=30.6-54) Gy. In patients with pelvic $\mathrm{LN}$ involvement $(\mathrm{N}=22)$, the median $\mathrm{RT}$ dose to the involved pelvic LN was 54 (range=45-60) Gy. Elective RT to the uninvolved inguinal $\mathrm{LN}$ area was performed in 70 patients, with a median RT dose of 45 (range=30.6-51) Gy. Patients with inguinal $\mathrm{LN}$ involvement $(\mathrm{N}=22)$ received a median RT dose to the involved inguinal LN of 50.4 (range=41.4-66) Gy. According to the RT technique, two-dimensional RT (2D-RT) was performed in 29 patients (34.9\%), three-dimensional conformal RT (3D-CRT) in $36(43.4 \%)$ and intensity-modulated RT (IMRT) in $18(21.7 \%)$.

Seventy-six patients $(91.6 \%)$ received concurrent chemotherapy, while seven patients $(8.4 \%)$ did not. The reasons for the omission of concurrent chemotherapy was that six patients were older than 70 years of age and one patient had an early stage cancer which their physician opted to treat without concurrent chemotherapy. Concurrent chemotherapy regimens consisted of FM in 63 patients $(75.9 \%)$, $5-\mathrm{FU}$ and cisplatin (FP) in nine patients $(10.8 \%)$ and 5-FU alone in four patients $(4.8 \%)$. FM regimen was applied as $1,000 \mathrm{mg} / \mathrm{m}^{2} /$ day 5 -FU intravenously from day 1 to day 4 and $10 \mathrm{mg} / \mathrm{m}^{2}$ mitomycin (as intravenous bolus on day 1 with repeat in weeks 1 and 5 . FP regimen was made up of the same dose of 5 -FU and $25 \mathrm{mg} / \mathrm{m}^{2} /$ day cisplatin intravenously from day 1 to day 4 in the same weeks as FM regimen. Only eight patients received additional chemotherapy after the completion of CCRT: FM in two patients, 5 FP in two patients, and fluoropyrimidine $\left(5-\mathrm{FU}, 900 \mathrm{mg} / \mathrm{m}^{2} /\right.$ day doxifluridine or 300 $\mathrm{mg} / \mathrm{m}^{2} /$ day tegafur-uracil) in four patients.
Table I. Patient and tumor characteristics.

\begin{tabular}{|c|c|}
\hline Characteristic & $\mathrm{N}(\%)$ \\
\hline \multicolumn{2}{|l|}{ Age, years } \\
\hline Median (range) & $64(36-86)$ \\
\hline \multicolumn{2}{|l|}{ Gender } \\
\hline Female & $62(74.7)$ \\
\hline Male & $21(25.3)$ \\
\hline \multicolumn{2}{|l|}{ ECOG PS } \\
\hline $0-1$ & $61(73.5)$ \\
\hline 2 & $12(14.5)$ \\
\hline N/A & $10(12.0)$ \\
\hline \multicolumn{2}{|l|}{ Tumor size } \\
\hline$\leq 4 \mathrm{~cm}$ & $49(59.0)$ \\
\hline$>4 \mathrm{~cm}$ & $23(27.7)$ \\
\hline $\mathrm{N} / \mathrm{A}$ & $11(13.3)$ \\
\hline \multicolumn{2}{|l|}{ T Stage } \\
\hline $\mathrm{T} 1$ & $15(18.1)$ \\
\hline $\mathrm{T} 2$ & $45(54.2)$ \\
\hline $\mathrm{T} 3$ & $16(19.3)$ \\
\hline $\mathrm{T} 4$ & $7(8.4)$ \\
\hline \multicolumn{2}{|l|}{ N Stage } \\
\hline No & $48(57.8)$ \\
\hline N1a & $32(38.6)$ \\
\hline $\mathrm{N} 1 \mathrm{~b}$ & $0(0.0)$ \\
\hline $\mathrm{N} 1 \mathrm{c}$ & $3(3.6)$ \\
\hline \multicolumn{2}{|c|}{ Internal iliac or mesorectal LN } \\
\hline Negative & $61(73.5)$ \\
\hline Positive & $22(26.5)$ \\
\hline \multicolumn{2}{|l|}{ External iliac LN } \\
\hline Negative & $80(96.4)$ \\
\hline Positive & $3(3.6)$ \\
\hline \multicolumn{2}{|l|}{ Inguinal LN } \\
\hline Negative & $61(73.5)$ \\
\hline Positive & $22(26.5)$ \\
\hline \multicolumn{2}{|c|}{ Stage by AJCC 8th edition } \\
\hline I & $13(15.7)$ \\
\hline II & $32(38.6)$ \\
\hline III & $38(45.8)$ \\
\hline
\end{tabular}

ECOG PS: Eastern Cooperative Oncology Group performance status; N/A: not available; AJCC: American Joint Committee on Cancer; LN: lymph node.

Statistical analysis. All outcomes were calculated from the start date of RT. Treatment response was defined as complete remission (CR) for disappearance of disease, partial remission for at least a $30 \%$ decrease, and progressive disease for at least a $20 \%$ increase in main disease. OS, PFS, locoregional PFS and distant metastasis-free survival (DMFS) were defined as the interval from the start date of RT to death, the date of relapse, the date of locoregional progression and the date of distant metastasis or the last follow-up, respectively. Toxicity was evaluated using the National Cancer Institute Common Terminology Criteria for Adverse Events ver. 4.0 (11). The KaplanMeier method was used to calculate the actuarial rates of OS, PFS, locoregional PFS and DMFS. For comparisons between groups, two-sided log-rank tests were performed. Multivariate analysis was carried out using the Cox proportional hazards model with prognostic factors with a $p$-value of less than 0.2 on univariate 

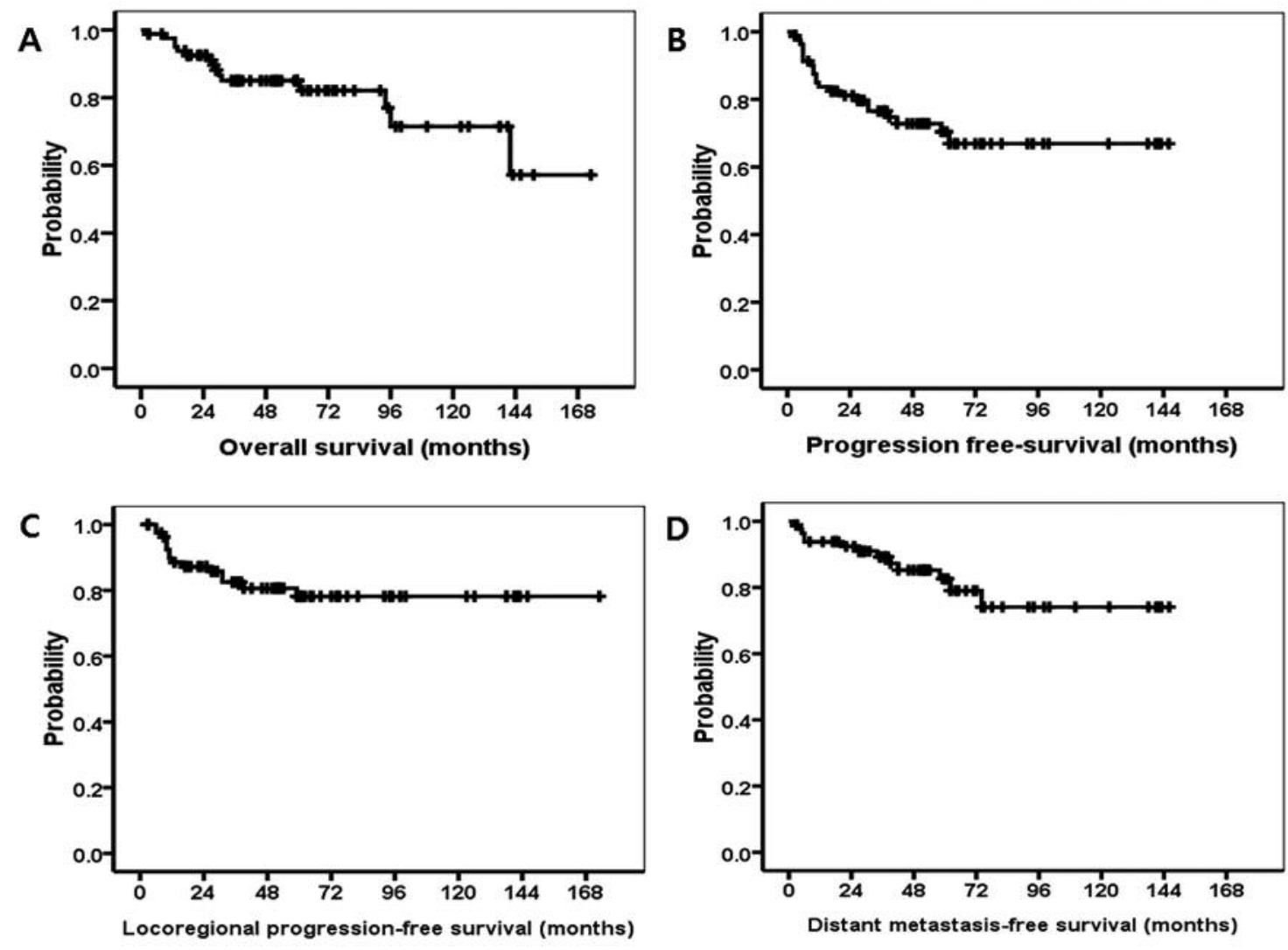

Figure 1. Kaplan-Meier curves for overall (A), progression-free (B), locoregional progression-free $(C)$ and distant metastasis-free (D) survival.

analysis. All tests were bilateral and statistical significance was determined when the $p$-value was less than 0.05 . All statistical analyses were performed using SPSS version 18.0 (SPSS, Inc., Chicago, IL, USA).

\section{Results}

Patient characteristics. Table I summarizes patient and tumor characteristics. The median age of patients overall was 64 (range $=36-86$ ) years. Gender distribution was femaledominant (female:male=62:21). Sixty-one patients $(73.5 \%)$ had an Eastern Cooperative Oncology Group performance status of zero or one. Forty-nine patients $(59.0 \%)$ had a tumor size of $\leq 4 \mathrm{~cm}$. The $\mathrm{T}$ stage, according to the 8 th edition of the classification of the American Joint Committee on Cancer (12), was T1-2 in 60 patients (72.3\%) and T3-4 in $23(27.7 \%)$. Thirty-five patients $(42.2 \%)$ had nodal involvement. Overall, the clinical stage was I in 13 patients $(15.7 \%)$, II in $32(38.6 \%)$, and III in 38 (45.8\%).

Response and patterns of failure. The median duration of follow-up was 51 (range=3-173) months. After the completion of RT, the initial treatment response was evaluated at a median follow-up of 1 month. Forty-nine patients $(59.0 \%)$ had CR, $33(39.8 \%)$ had partial remission and one $(1.2 \%)$ had progressive disease. Among the patients with partial remission, 25 attained CR with follow-up. Therefore, a total of 74 patients $(89.2 \%)$ were found to have $\mathrm{CR}$ at a median follow-up of 2 months.

Five patients $(22.7 \%)$ had isolated local recurrence, four (18.2\%) had isolated regional recurrence, seven $(31.8 \%)$ had isolated distant metastasis and six $(27.3 \%)$ had regional recurrence plus distant metastasis. The specific sites of regional LN recurrence were as follows: inguinal $(\mathrm{N}=3)$, internal iliac $(\mathrm{N}=1)$, external iliac $(\mathrm{N}=1)$, mesorectal $(\mathrm{N}=1)$ and multiple sites $(\mathrm{N}=4)$. Thirteen patients did not receive elective RT to the inguinal LN area. Among these patients, only one $(7.7 \%)$ experienced bilateral inguinal $\mathrm{LN}$ recurrences. Among 70 patients treated with elective RT to uninvolved inguinal LN area, only one patient (1.4\%) had an inguinal LN recurrence. Thirteen patients experienced distant metastasis at 17 sites: distant $\mathrm{LN}(\mathrm{N}=6)$, liver $(\mathrm{N}=4)$, lung $(\mathrm{N}=4)$, bone $(\mathrm{N}=2)$ and skin $(\mathrm{N}=1)$. 
Table II. Univariate analysis for 5-year overall (OS), progression-free (PFS), locoregional progression-free (LPFS) and distant metastasis-free (DMFS) survival.

\begin{tabular}{|c|c|c|c|c|c|c|c|c|c|}
\hline & $\mathrm{N}$ & OS $(\%)$ & $p$-Value* & PFS (\%) & $p$-Value* & LPFS (\%) & $p$-Value* & DMFS $(\%)$ & $p$-Value* \\
\hline \multicolumn{10}{|l|}{ Age } \\
\hline$\leq 64$ Years & 45 & 79.9 & \multirow[t]{2}{*}{0.377} & 59.3 & \multirow[t]{2}{*}{0.153} & 66.4 & \multirow[t]{2}{*}{0.033} & 75.6 & \multirow[t]{2}{*}{0.430} \\
\hline$>64$ Years & 38 & 91.2 & & 82.6 & & 91.2 & & 88.5 & \\
\hline \multicolumn{10}{|l|}{ Gender } \\
\hline Female & 62 & 83.6 & \multirow[t]{2}{*}{0.981} & 64.1 & \multirow[t]{2}{*}{0.130} & 74.5 & \multirow[t]{2}{*}{0.234} & 80.2 & \multirow[t]{2}{*}{0.329} \\
\hline Male & 21 & 89.4 & & 88.7 & & 88.7 & & 90.9 & \\
\hline \multicolumn{10}{|l|}{ ECOG PS ${ }^{\dagger}$} \\
\hline $0-1$ & 61 & 85.4 & \multirow[t]{2}{*}{0.907} & 73.9 & \multirow[t]{2}{*}{0.848} & 80.2 & \multirow[t]{2}{*}{0.862} & 82.6 & \multirow[t]{2}{*}{0.912} \\
\hline 2 & 12 & 90.0 & & 71.3 & & 80.0 & & 78.6 & \\
\hline \multicolumn{10}{|l|}{ Tumor size $^{\dagger}$} \\
\hline$\leq 4 \mathrm{~cm}$ & 49 & 88.4 & \multirow[t]{2}{*}{0.145} & 71.4 & \multirow[t]{2}{*}{0.243} & 78.4 & \multirow[t]{2}{*}{0.554} & 84.1 & \multirow[t]{2}{*}{0.187} \\
\hline$>4 \mathrm{~cm}$ & 23 & 76.0 & & 57.9 & & 70.0 & & 68.7 & \\
\hline \multicolumn{10}{|l|}{ T Stage } \\
\hline $\mathrm{T} 1-2$ & 60 & 90.7 & \multirow[t]{2}{*}{0.123} & 73.1 & 0.452 & 80.6 & 0.497 & 85.2 & 0.384 \\
\hline T3-4 & 23 & 70.3 & & 62.4 & & 70.9 & & 73.5 & \\
\hline $\mathrm{LN}$ & & & & & & & & & \\
\hline Negative & 48 & 87.7 & 0.986 & 87.7 & 0.136 & 82.2 & 0.369 & 91.6 & 0.074 \\
\hline Positive & 35 & 81.7 & & 62.4 & & 73.0 & & 69.8 & \\
\hline Stage & & & & & & & & & \\
\hline I & 13 & 85.7 & 0.799 & 85.7 & 0.147 & 87.5 & 0.395 & 100.0 & 0.271 \\
\hline II & 32 & 84.3 & & 73.9 & & 82.2 & & 87.1 & \\
\hline III & 38 & 80.5 & & 63.0 & & 72.9 & & 72.1 & \\
\hline RT technique & & & & & & & & & \\
\hline $2 \mathrm{D}$ & 29 & 81.1 & 0.425 & 63.8 & 0.270 & 74.5 & 0.707 & 71.1 & 0.022 \\
\hline 3D-CRT/IMRT & 54 & 87.7 & & 75.2 & & 82.0 & & 90.5 & \\
\hline RT technique & & & & & & & & & \\
\hline 2D/3D-CRT & 65 & 84.9 & 0.996 & 68.4 & 0.493 & 75.2 & 0.204 & 83.8 & 0.420 \\
\hline IMRT & 18 & 88.9 & & 82.1 & & 94.1 & & 82.1 & \\
\hline Treatment period & & & & & & & & & \\
\hline$\leq 2007$ & 39 & 83.5 & 0.976 & 65.2 & 0.334 & 76.1 & 0.775 & 75.2 & 0.086 \\
\hline$>2007$ & 44 & 86.9 & & 78.7 & & 83.1 & & 92.8 & \\
\hline Total dose & & & & & & & & & \\
\hline$\leq 54.0 \mathrm{~Gy}$ & 40 & 80.3 & 0.182 & 73.3 & 0.918 & 75.4 & 0.257 & 88.1 & 0.308 \\
\hline$>54.0 \mathrm{~Gy}$ & 43 & 89.1 & & 69.7 & & 82.4 & & 79.6 & \\
\hline Concurrent $\mathrm{CTx}^{\ddagger}$ & & & & & & & & & \\
\hline FM & 63 & 86.1 & 0.373 & 72.0 & 0.680 & 80.6 & 0.193 & 79.5 & 0.098 \\
\hline Other & 13 & 82.1 & & 64.8 & & 64.8 & & 100.0 & \\
\hline Initial treatment $\mathrm{re}$ & & & & & & & & & \\
\hline $\mathrm{CR}$ & 49 & 90.9 & 0.252 & 76.3 & 0.039 & 82.9 & 0.162 & 89.6 & 0.007 \\
\hline Non-CR & 34 & 75.8 & & 63.0 & & 72.1 & & 71.1 & \\
\hline Eventual treatmen & & & & & & & & & \\
\hline $\mathrm{CR}$ & 74 & 89.1 & 0.037 & 75.9 & $<0.001$ & 83.3 & $<0.001$ & 87.4 & $<0.001$ \\
\hline Non-CR & 9 & 53.3 & & 25.4 & & 37.5 & & 38.1 & \\
\hline
\end{tabular}

ECOG PS: Eastern Cooperative Oncology Group performance status; LN: lymph node; RT: radiotherapy; 2D: Two-dimensional radiotherapy; 3DCRT: three-dimensional conformal radiotherapy; IMRT: intensity modulated radiotherapy; CTx: chemotherapy; FM: 5-fluorouracil plus mitomycin C; CR: complete remission. ${ }^{*}$ Log-rank test; ${ }^{\dagger}$ Analysis with available data; $¥$ Patients with no chemotherapy were not included.

Survival and prognostic factors. The actuarial 5-year OS, PFS, locoregional PFS and DMFS were $85.0 \%, 70.4 \%$, $78.2 \%$ and $82.6 \%$, respectively (Figure 1 ). Table II shows prognostic factors in univariate analysis for 5-year OS, PFS, locoregional PFS and DMFS. Univariate analysis indicated that eventual treatment response $(89.1 \%$ for CR vs. $53.3 \%$ for non-CR; $p=0.037$ ) was the only significant risk factor for OS. As for PFS, initial treatment response $(76.3 \%$ for CR vs. $63.0 \%$ for non-CR; $p=0.039$ ) and eventual treatment response $(75.9 \%$ for CR $v s .25 .4 \%$ for non-CR; $p<0.001)$ were significant risk factors. Younger age $(66.4 \%$ for $\leq 64$ years $v s .91 .2 \%$ for $>64$ years; $p=0.033$ ) and eventual non- 

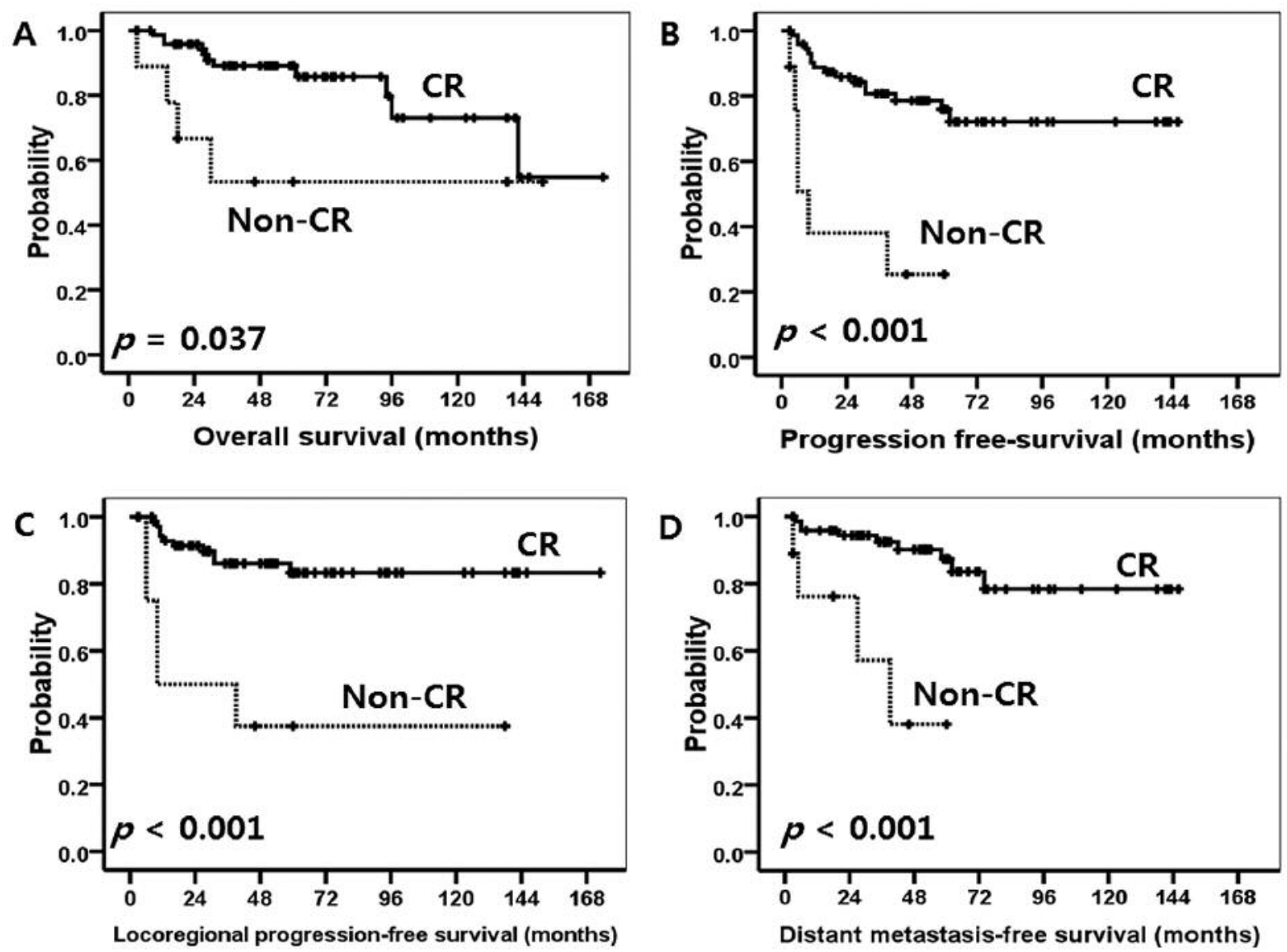

Figure 2. Kaplan-Meier curves for overall (A), progression-free (B), locoregional progression-free $(C)$ and distant metastasis-free $(D)$ survival according to eventual treatment response. CR: Complete remission.

CR treatment response $(83.3 \%$ for CR vs. $37.5 \%$ for non$\mathrm{CR} ; p<0.001)$ were associated with worse locoregional PFS. 3D-CRT or IMRT technique $(71.1 \%$ for 2D-RT vs. $90.5 \%$ for 3D-CRT or IMRT; $p=0.022)$, initial CR treatment response $(89.6 \%$ for $\mathrm{CR} v s .71 .1 \%$ for non-CR; $p=0.007)$ and eventual CR treatment response $(87.4 \%$ for CR $v s$. $38.1 \%$ for non-CR; $p<0.001)$ were correlated with better DMFS (Figure 2).

Multivariate analysis showed that eventual treatment response was the only significant prognosticator for OS $(p=0.023)$ and PFS $(p<0.001)$. Younger age $(p=0.013)$ and eventual non-CR treatment response $(p<0.001)$ were significant risk factors for worse locoregional PFS. Initial non-CR treatment response, $\mathrm{LN}$ involvement and 2D-RT technique were significantly associated with worse DMFS ( $p=0.016,0.048$ and 0.002 , respectively).

Toxicity. Table III reports toxicity profiles. Each event was counted regardless of other events, and the highest grade of observed complications was recorded. Hematological toxicity occurred mainly in the acute phase. The most
Table III. Complications of grade 3 or more by the Common Terminology Criteria for Adverse Events 4.0 according to radiotherapy modality.

\begin{tabular}{lllll}
\hline & \multicolumn{3}{c}{ Acute, n (\%) } & Late, n (\%)* \\
\cline { 2 - 3 } Complication & \multicolumn{1}{c}{$2 \mathrm{D}$} & 3D-CRT & IMRT & IMRT \\
\hline Hematological & & & & \\
$\quad$ Anemia & $2(6.9)$ & $1(2.8)$ & & \\
$\quad$ Leukopenia & $6(20.7)$ & $5(13.9)$ & $3(16.7)$ & \\
$\quad$ Thrombocytopenia & $3(10.3)$ & $3(8.3)$ & $2(11.1)$ & \\
Non-hematological & & & & \\
$\quad$ Skin & $4(13.8)$ & $1(2.8)$ & $1(5.6)$ & \\
$\quad$ Gastrointestinal & & $1(2.8)$ & & $1(2.8)$ \\
$\quad$ Genitourinary & & & & \\
\hline
\end{tabular}

2D: Two-dimensional radiotherapy; 3D-CRT: three-dimensional conformal radiotherapy; IMRT: intensity modulated radiotherapy. *No other late grade 3 or more complications were recorded.

common non-hematological toxicity was dermatitis. Only one grade 3 toxicity event occurred in the late phase. 


\section{Discussion}

In the present study, we performed a multicenter, retrospective analysis of anal cancer treated with definitive RT. Most patients received the current standard treatment, that is, CCRT with an FM regimen, and the outcomes were comparable to previous reports. Locoregional progression was the dominant failure pattern, and eventual treatment response evaluated at a median of 2 months after the completion of RT was a prognostic factor predicting all outcomes except DMFS on multivariate analysis. In addition, initial treatment response and RT technique were significantly associated with DMFS.

The optimal timing of treatment-response evaluation is a critical yet debated factor in the treatment of anal cancer. In the initial randomized trials, it was recommended that patients with a poor response at 6 weeks after the completion of RT should have salvage surgery $(5,6)$. The current National Comprehensive Cancer Network guidelines recommend an evaluation at 8-12 weeks (13). However, in the ACT II phase III trial, clinical response was assessed prospectively at 11,18 and 26 weeks after CCRT. Patients with CR at 18 and 26 weeks after CCRT had superior 5-year OS and PFS compared to those without $\mathrm{CR}$, suggesting that deciding on $\mathrm{CR}$ can be delayed until 6 months after CCRT if the disease is not progressive (14). In a retrospective study in Korea, Kim et al. assessed clinical response at 4 weeks and 6 months after RT and demonstrated that the 6-month response was a marginally significant prognosticator for PFS $(p=0.090)$, based on univariate analysis (15). In our study, we evaluated both initial and eventual responses as risk factors and the eventual response was an independent prognosticator affecting OS, PFS and locoregional PFS. The initial response affected DMFS. Some discrepancy between the ACT II trial and the current study may be explained in part by the observation that $89.2 \%$ of our patients attained CR at a median follow-up of 2 months, which was much higher than in the ACT II trial, where patients attained a CR rate of only $64 \%$ at 11 weeks after CCRT. Although the ACT II trial prospectively evaluated the treatment response while our study did not, the higher RT dose used in our study (median 55 Gy vs. 50.4 Gy in ACT II trial) might have contributed to the higher CR rate at the earlier time.

Regarding the RT technique, we observed that 2D-RT was associated with an inferior DMFS. A similar observation was reported in nasopharyngeal cancer: 3D-CRT or IMRT led to superior 5-year OS than did 2D-RT (16), and IMRT achieved superior DMFS than 2D-RT with borderline significance (17). Anal cancer is a representative case where IMRT is preferred for the complex target coverage (18). Two Radiation Therapy Oncology Group studies were compared indirectly regarding the toxicity of IMRT versus 2D-RT, and it was found that IMRT toxicity profiles were better (19). Recently, a study using the National Cancer Database revealed that IMRT was superior to $3 \mathrm{D}-\mathrm{CRT}$ in terms of OS $(p=0.0036)$. On multivariate analysis, IMRT retained its significance for death with a hazard ratio of $0.85(p=0.0049)$ (20). In the current study, we showed that all of the outcomes, including OS, PFS, locoregional PFS and DFMS, were inferior in patients treated with 2D-RT, although the difference was significant only for DMFS. Thus, advances in RT technique might potentially reduce treatment-related toxicities as well as improve treatment outcomes.

The optimal RT field has not yet been established despite RT being the mainstay of anal cancer treatment. The role of elective RT to the inguinal LN area has been particularly controversial. In the present study, among the 13 patients who did not receive RT to uninvolved inguinal $\mathrm{LN}$ area, only one patient $(7.7 \%)$ had an inguinal failure. Moreover, among 70 patients who underwent elective inguinal RT, only one patient (1.4\%) had an inguinal recurrence. Kim et al. proposed the omission of prophylactic inguinal RT because they observed no inguinal failure in their retrospective study of 33 patients who received no prophylactic inguinal RT (21). On the other hand, Thompson et al. examined the feasibility of inguinal observation in a retrospective chart review of 51 patients. Because they observed no inguinal failure in the elective inguinal RT group compared with a $23 \%$ inguinal failure rate in the observation group $(p=0.009)$, the authors recommended treating every patient with elective inguinal RT (22). Many researchers have been trying to determine which patients do not need elective inguinal RT, and patients with T1-2N0 disease are generally considered suitable (23). In the current study, 10 patients (76.9\%) with $\mathrm{T} 1-2$ and nine patients $(69.2 \%)$ with N0 disease were among the 13 patients without elective inguinal RT. Although the crude inguinal failure rate was higher in the group that received no elective inguinal RT, we were unable to make any definitive conclusion because of the small number of events.

The optimal RT dose is another source of controversy. In randomized trials, the prescribed dose to the primary tumor was usually 45-50.4 Gy $(5-7,9)$. The ACCORD-3 trial compared a standard dose of 15 Gy with a high dose of 20-25 Gy boost after $45 \mathrm{~Gy}$ in 25 fractions. The 5-year colostomy-free survival was $73.7 \%$ for the standard-boost group versus $77.8 \%$ for the high-boost group ( $p=0.067)(10)$. In a retrospective study by Ferrigno et al., a dose of more than 50 Gy to the primary tumor achieved better local control (24). In the current study, most patients received an RT dose $\geq 50 \mathrm{~Gy}$, with a dose of $54 \mathrm{~Gy}$ having no impact on any of the outcomes. The PALTO trial in the United Kingdom is underway to test dose escalation for high-risk and dose de-escalation for low- to intermediate-risk patients (25).

Limitations of the current study include that we cannot exclude selection bias, and we might have underestimated the rate of late complications due to the retrospective nature of the study. However, we collected a relatively large number 
of patients who received the current standard therapy, and these data might provide the opportunity to compare the outcomes from randomized trials and those from real-world practice, especially from Asia.

In conclusion, this study shows that for anal squamous cell carcinoma, RT mainly combined with concurrent chemotherapy achieved CR in most patients without serious complications. Eventual treatment response is an important predictor for outcomes, and therefore further optimization regarding RT dose and field is needed to improve treatment responses.

\section{Conflicts of Interest}

There was no conflict of interest related to this article.

\section{References}

1 Siegel RL, Miller KD and Jemal A: Cancer statistics, 2018. CA Cancer J Clin 68: 7-30, 2018.

2 The Korea Central Cancer Registry, National Cancer Center, Ministry of Health and Welfare. Annual Report of Cancer Statistics in Korea in 2015. Available via http://ncc.re.kr. (Accessed October 2018).

3 Nigro ND, Vaitkevicius VK, Considine B Jr.: Combined therapy for cancer of the anal canal: A preliminary report. Dis Colon Rectum 17: 354-356, 1974.

4 Glynne-Jones R, Nilsson PJ, Aschele C, Goh V, Peiffert D, Cervantes A and Arnold D: Anal cancer: ESMO-ESSO-ESTRO Clinical Practice Guidelines for diagnosis, treatment and followup. Eur J Surg Oncol 40: 1165-1176, 2014.

5 UKCCCR Anal Cancer Trial Working Party. UK Co-ordinating Committee on Cancer Research. Epidermoid anal cancer: Results from the UKCCCR randomised trial of radiotherapy alone versus radiotherapy, 5-fluorouracil, and mitomycin. Lancet 348: 1049-1054, 1996.

6 Bartelink H, Roelofsen F, Eschwege F, Rougier p, Bosset JF, Gonzalez DG, Peiffert D, van Glabbeke $\mathrm{M}$ and Pierart $\mathrm{M}$ : Concomitant radiotherapy and chemotherapy is superior to radiotherapy alone in the treatment of locally advanced anal cancer: results of a phase III randomized trial of the European Organization for Research and Treatment of Cancer Radiotherapy and Gastrointestinal Cooperative Groups. J Clin Oncol 15: 2040-2049, 1997.

7 Flam M, John M, Pajak TF, Petrelli N, Myerson R, Doggett S, Quivey J, Rotman M, Kerman H, Coia L and Murray K: Role of mitomycin in combination with fluorouracil and radiotherapy, and of salvage chemoradiation in the definitive nonsurgical treatment of epidermoid carcinoma of the anal canal: Results of a phase III randomized intergroup study. J Clin Oncol 14: 25272539, 1996.

8 Gunderson LL, Winter KA, Ajani JA, Pedersen JE, Moughan J, Benson AB 3rd, Thomas CR Jr, Mayer RJ, Haddock MG, Rich TA and Willett CG: Long-term update of US GI Intergroup RTOG 98-11 phase III trial for anal carcinoma: survival, relapse, and colostomy failure with concurrent chemoradiation involving fluorouracil/mitomycin versus fluorouracil/cisplatin. J Clin Oncol 30: 4344-4351, 2012.
9 James RD, Glynne-Jones R, Meadows HM, Cunningham D, Myint AS, Saunders MP, Maughan T, McDonald A, Essapen S, Leslie M, Falk S, Wilson C, Gollins S, Begum R, Ledermann J, Kadalayil L and Sebag-Montefiore D: Mitomycin or cisplatin chemoradiation with or without maintenance chemotherapy for treatment of squamous-cell carcinoma of the anus (ACT II): A randomised, phase 3 , open-label, $2 \times 2$ factorial trial. Lancet Oncol 14: 516-524, 2013.

10 Peiffert D, Tournier-Rangeard L, Gérard JP, Lemanski C, François E, Giovannini M, Cvitkovic F, Mirabel X, Bouché O, Luporsi E, Conroy T, Montoto-Grillot C, Mornex F, Lusinchi A, Hannoun-Lévi JM, Seitz JF, Adenis A, Hennequin C, Denis $B$ and Ducreux $M$ : Induction chemotherapy and dose intensification of the radiation boost in locally advanced anal canal carcinoma: Final analysis of the randomized UNICANCER ACCORD 03 trial. J Clin Oncol 30: 1941-1948, 2012.

11 NCI Common Terminology Criteria for Adverse Events (CTCAE) v.4 data files. Bethesda, MD: National Cancer Institute. Available via http://evs.nci.nih.gov/ftp1/CTCAE/About .html. (Accessed October 2018)

12 Amin MB, Edge S, Greene F, Byrd DR, Brookland RK, Washington MK, Gershenwald JE, Compton CC, Hess KR, Sullivan DC, Jessup JM, Brierley JD, Gaspar LE, Schilsky RL, Balch CM, Winchester DP, Asare EA, Madera M, Gress DM and Meyer LR (eds.): AJCC Cancer Staging Manual (8th edition). Springer International Publishing: American Joint Commission on Cancer, pp. 275-284, 2017.

13 National Comprehensive Cancer Network. Anal Carcinoma (Version 2. 2018). Available via https://www.nccn.org/ professionals/physician_gls/pdf/anal.pdf. (Accessed October 2018)

14 Glynne-Jones R, Sebag-Montefiore D, Meadows HM, Cunningham D, Begum R, Adab F, Benstead K, Harte RJ, Stewart J, Beare S, Hackshaw A, Kadalayil L, ACT II Study Group: Best time to assess complete clinical response after chemoradiotherapy in squamous cell carcinoma of the anus (ACT II): A post-hoc analysis of randomised controlled phase 3 trial. Lancet Oncol 18: 347-356, 2017.

$15 \mathrm{Kim} \mathrm{KH,} \mathrm{Chang} \mathrm{JS,} \mathrm{Keum} \mathrm{KC,} \mathrm{Ahn} \mathrm{JB,} \mathrm{Lee} \mathrm{CG} \mathrm{and} \mathrm{Koom}$ WS: Chemoradiotherapy in squamous cell carcinoma of the anal canal: a single institution experience. Radiat Oncol J 31: 25-33, 2013.

16 Moon SH, Cho KH, Lee CG, Keum KC, Kim YS, Wu HG, Kim JH, Ahn YC, Oh D and Lee JH: IMRT vs. 2Dradiotherapy or 3D-conformal radiotherapy of nasopharyngeal carcinoma: Survival outcome in a Korean multi-institutional retrospective study (KROG 11-06). Strahlenther Onkol 192: 377-385, 2016

17 Zhang MX, Li J, Shen GP, Zou X, Xu JJ, Jiang R, You R, Hua YJ, Sun Y, Ma J, Hong MH and Chen MY: Intensitymodulated radiotherapy prolongs the survival of patients with nasopharyngeal carcinoma compared with conventional twodimensional radiotherapy: A 10-year experience with a large cohort and long follow-up. Eur J Cancer 51: 2587-2595, 2015.

18 Sakanaka K, Itasaka S, Ishida Y, Fujii K, Horimatsu T, Mizowaki T, Sakai Y and Hiraoka M: Dosimetric advantages and clinical outcomes of simultaneous integrated boost intensitymodulated radiotherapy for anal squamous cell carcinoma. Radiat Oncol J 35: 368-379, 2017. 
19 Kachnic LA, Winter K, Myerson RJ, Goodyear MD, Willins J, Esthappan J, Haddock MG, Rotman M, Parikh PJ, Safran H and Willett CG: RTOG 0529: A phase 2 evaluation of dose-painted intensity-modulated radiation therapy in combination with 5fluorouracil and mitomycin- $\mathrm{C}$ for the reduction of acute morbidity in carcinoma of the anal canal. Int J Radiat Oncol Biol Phys 86: 27-33, 2013.

20 Elson JK, Kachnic LA and Kharofa JR: Intensity-modulated radiotherapy improves survival and reduces treatment time in squamous cell carcinoma of the anus: A National Cancer Data Base study. Cancer, 2018. doi:10.1002/cncr.31721.

21 Kim H, Park HC, Yu JI, Choi DH, Ahn YC, Kim ST, Park JO, Park YS and Kim HC: Can we omit prophylactic inguinal nodal irradiation in anal cancer patients? Radiat Oncol J 33: 83-88, 2015.

22 Thompson SR, Lee ISY, Carroll S, Bishop S, Douglas p, Lam F, Brown C5, Williams J1, Goldstein D: Radiotherapy for anal squamous cell carcinoma: Must the upper pelvic nodes and the inguinal nodes be treated? ANZ J Surg 88: 870-875, 2018.
23 Matthews JH, Burmeister BH, Borg M, Capp AL, Joseph D, Thompson KM, Thompson PI, Harvey JA and Spry NA: T1-2 anal carcinoma requires elective inguinal radiation treatmentThe results of Trans Tasman Radiation Oncology Group study TROG 99.02. Radiother Oncol 98: 93-98, 2011.

24. Ferrigno R, Nakamura RA, Dos Santos Novaes PE, Pellizzon AC, Maia MA, Fogarolli RC, Salvajoli JV, Filho WJ and Lopes A: Radiochemotherapy in the conservative treatment of anal canal carcinoma: retrospective analysis of results and radiation dose effectiveness. Int J Radiat Oncol Biol Phys 61: 1136-1142, 2005.

25 ISRCTN Registry. PLATO - Personalising Anal Cancer Radiotherapy Dose. ISRCTN88455282. Available via http://www.isrctn .com/ISRCTN88455282?q=\&filters $=\&$ sort $=\&$ offset $=6 \&$ totalResults $=14867 \&$ page $=1 \&$ pageSize $=10 \&$ searchT ype=basic-search. (Accessed October 2018).

Received October 23, 2018

Revised October 31, 2018

Accepted November 1, 2018 